\title{
Theisme Dalam Bhagavadgita
}

\section{Titi Surti Nastiti}

Keywords: philology, archaeology, history, theism, hermeneutics

\section{How to Cite:}

Nastiti, T. Surti (1993). Theisme Dalam Bhagavadgita. Berkala Arkeologi, 13(1),

22-34. https:// doi.org/10.30883/jba.v13i1.563

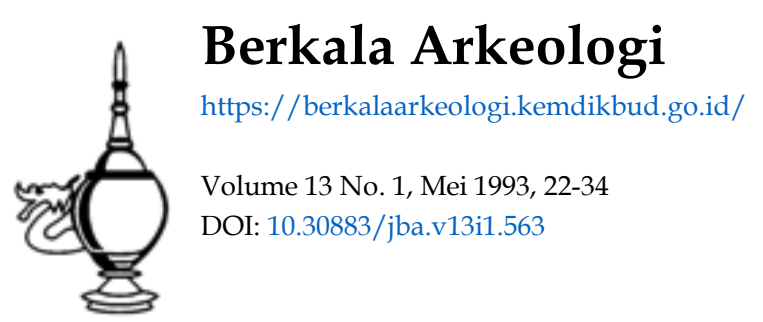




\section{THEISME DALAM BHAGAVADGITA}

Oleh. Tut Suti Nastur

\section{Bhacuradgî́n}

Bhagavadgîtâ yang merupakan baglan dart Bhîsmaparva dan juga baglan dart cerita eplk Mahăbhårata adalah puist keagamaan yang palling terkenal dalam kesusastraan Sansekerta (Radhaknshnan 1929:519). Bhagavadgitã yang berart Nyanytan Tuhan Inl adalah sebuah karya yang berupa smọtl sâstra (Dasgupta 1952:438; Radhakrionan 1929:519), artinya bahwa kdtab Inl dlaku sebagal clptaan manusla dan bukan sebagal wahyu. Karya vang pada Intinya berisi dialog antara Kự̣na sebagal titisan Viṣnu dengan Arjuna pada awal perang Bhâratayuddha Int sangat berpengaruh pada permiktran bangsa Indla. Dialog itu terjadi ketlka pasukan Pândava dan Kaurava telah berhadapan di medan perang Kuruksetra. Arjuna ragu-ragu untuk berperang melawan pthak Kaurava yang juga adalah saudara-saudaranya, gurunya dan sahabat-sahabatnya. Krọna yang mellhat hal tersebut kemudian memanggil Arjuna dan membert ajaran tentang kewajiban-kewajlban yang harus dilaksanakan oleh setlap kasta (Brahmana. Kșatrya. Vais'ya. dan S'udral atau suadharnma. Jika Arjuna tidak mau berperang yang merupakan kewajtban kaum Kṣatrya. maka la tłdak hanya kehllangan kehormatan dan reputasinya. tapl juga akan dicemoohkan dan dihina (Dasgupta 1952:502: Hadtwljono 1985:47: Radhakrishnan 1929:520-521).

Penulis Bhagavadgitâ menulis kitab Inı tdak bermaksud untuk membuat gerakan misionar. mendirlkan sekte-sekte ataupun aliran-aliran tertentu. akan tetapl menampung semua ajaran-ajaran yang ada pada saat itu dan mencoba menerapkan dalam kehidupan sehari-hari. Seperti ilsebutkan oleh Radhakrishnan bahwa penulis Bhagavadgitâ mencoba menerapkan ajaran Upaniṣad ke dalam kehiciupan seharl-har dengan memasukkan mitologl dan pengembangan imajinasi vang berlaku bagl seluruh bangsa (Ra dhakrishnan 1929:522) atau oeperts vang dikatakan oleh Pudja bahwa Bhagavadgitá merupakan ketentuan ketentuan vang harus diperhatikan delam kehidupan seharthar aga kesejahteraan kedamatan serta keamanan dapat terwujud sehingga akhirnva akan membuka jalan selebar lebarnva menu|u alam kesempumaan IPudja 
1985/1986:LX. Bhagavadĝttâ yang menyampalkan ajaran fllsafat, agama, dan etlka muncul ketika hanya yang kaya yang dapat menyuap. Dewa-dewa dengan kurban dan hanya mereka yang terpelajar yang dapat mempelajar pengetahuan, Bhagavadgitâ mengajarkan suatu metode yang didalamnya mencapal tujuan akhtr dengan bhaktl (Radhakrishnan 1929:522).

Kitab Bhagavadgîtâ terdirt dart 18 bab, yaitu Arjuna Vlsada Yoga, Upanlṣad Sâthkhya Yoga, Kamma Yoga, Jñâna Yoga, Kamaa Samnyasa Yoga, Dhyâna Yoga. Vijñâna Yoga. Yogasâsíra-Akşara, Brahma Yoga. Râja Vidyâ Rajaguhyâ Yoga, Vibhûti Yoga. Visvarîipa Yoga. Kṣetra Kọetrâjnâ Yoga, Guṇa Traya Vibhaga Yoga. Punusottama Yoga, Datva Sura Sampad Vibhaga Yoga, S'raddha Traya Vibhaga Yoga dan Samnyasa Yoga (Pudja 1985/1986:XXIN). Yâmuna, guru darı Râmânuja yang lahır pada tałıun $906 \mathrm{M}$., membuat ringkasan Bhagavadgit ẩ yang berjudul Gîtâritha-

sarthgraha Dalam karyanya Int la menjabarkan ist Bhagavadgîtâ bab per bab. dimulal dart bab dua sebagal bertkut: Bab dua menjelaskan slfat orang sucl, yaltu kebajlkan yang sangat tenang (sthita-dhi). Pengetahuan yang benar hanya dapat diperoleh dengan mengenali dirl sendiri sebagal makhluk fana dan dengan menjalankan kewajtban dengan perasaan tudak tertkat. Bab tlga menjelaskan bahwa manusla harus menjalankan kewajlbannya untuk menjaga keteraturan soslal (loka-raksai) tanpa merasa terkat. menyerahkan hasll tundakannya pada kehendak Tuhan. serta pada saat yang sama menyadari bahwa gura lalah perantara tindakan yang sesungguhnya dan membanggakan preotas! pribadi lalah sifat yang tidak balk. Bab empat mendesikripolkan slfat-stfat Tuhan. bagaimana manusia di anjurkan untuk memandang tindakan sebagal secara tidak langsung bukan tindakan (karena sifiat ketidakterikatannya), serta menjelaakan berbagal jenis kewajlban manusla dan kemuliaan pengetahuan. Bab lima memuat berbagal manfaat dan cara melaksanakan jalan kewajlban. eerta olfat dart kondisi kesadaran Bratmar Bab enam menjelaskan tentang otfat latihan yoga empat jente yogin, bertagal metode yoga slfat realloasl yoga. dan keunggulan utama yogo dalar hubungannya dengan Tuhan. Bab tujuh mengyambarkan keagungan Tuhan dan realitas stfatNya sebagal (zat) yang tetap dan Udak benibah-ubah. Selain itu juga merideakripalkan kewajtban-kewajtban umat manusla yang 
berlindung pada Tuhan dan slfat kewallban sejat Bab sembllan mendeskripalkan keagungan iuhan, superloritasNya. bahkan dalam bentuk inkamasiNya sebagal manusla, dan hubungan yang bersifat tbadah Bab sepuluh menuliskan olfat-sifat agung Tuhan yang tidak terbatas serta ketergantungan semua makhiuk kepadaNya. meningkatkan pemujaan kepadaNya. Bab sebeias menjelaskan bagalmana sifat Tuhan sesungguhnya dapat dimengert, serta menunjukkan bahwa Tuhan hanya dapat dipahaml atau dicapal melalui pemujaan kepadaNya. Bab duabelas menerangkan superioritas pemujaan. metode-metode pemujaan. dan berbagal jenls gemujaan. Dalam bab int juga disebutkan bahwa manusia dapat membuat Tuhan senang dengan cara memujaivya. Bab tigabelas menggambarkan stfat tubuh dan penyuclan dirl dalam rangka pengenalan dirl yang menimbulkan keterikatan dan diskriminasi yang benar Bab empatbelas menjelaskan cara bagalmana sifat darı suatu tIndakan ditentukan oleh ikatan-lkatan gura cara mengurangl pengaruh gura pada manusla, serta menyatakan bahwa hanya Tuhan-lah asal dart segala jalan menuju takdir manusla dimasa yang akan datang. Bab limabelas menerangkan bahwa Thana berbeda dart jatl dirl yang muml serta darl jatl dirl dalam hubungannya dengan zat diluar Jatı dirınya. yang berkaltan dengan peresapannya dan elfatnya sebagal umat dan penclpta. Bab enambelas mendeskripstkan pembaglan makhluk ke dalam yang batk dan buruk. serta poslst terpllih ktab sucl sebagal sumber untuk menerangikan dasar yang kuat dart pengetahuan akan bersifat kewajtban-kewajtban manusta yang sesungguhnya. Bab tujuhbelas membedakan benda-benda sakral dan profan. Bab clelapanbelas menjelaskan bahwa hanya Tuhan yang harus dihornaul sebagal zat yang tertinggl dart segala tundakan dan menyatakan perlunya kesuctan dan otfiat dart pengaruh tindakan manusla (Dasgupta. 1952:439-440).

Menurut Talboys Wheeler. Bhagavadgitâ adalah teks yang disisipican pada pertode kemudilan setelah penulisan Mahābhârata Pendapatnya Int didukung oleh Telang dalam S.B.E vol VIII:5-6 yang menyebutkan bahwa Bhagavadgitâ merupakan karya tersendir (Radhakulshnan 1929:523) Mesklpun disebutkan bahwa Bhagavadgîtê ditulis perlode yang berlain dengan Mahâbhârata. akan tetapl jlka mellhat komposiol certta Bhagavadgitâ adalah bağlan asll dart cerita Mahâbhârata Sehubungan dengan pendapat 
tereebut, Tllak dalam Gî̀a-nahasya menyebulkan bahwa persamaan gaya bahasa yang dipakal dalam Mahâbhârata dan Bhagavadgî́â memperthatkan keduanya menupakan satu kesatuan. Dalam beberapa pandangan mengenal ajaran-ajaran dart flsafat dan agama dalam Mahâbhârata dan Bagavadgîtâ kurang lebih sama, mloalnya mengenal karma yang leblh dipllh dart pada akama (B.G. bab III; Varnparia bab XaXM. pendirlan tentang kurban yang terdapat dalam ajaran Veda (Santporva 267; Mare bab IIf), pernyataan tentang aturan penciptaan (B.G. bab VI. VW: Santtparua: 231), teorl Sânkkhya mengenal guna (B.G. bab XTV. XV; Aśvamedhaparva : 36-39. Santparva : 285, 300-30 1). Patanjall Yoga (B.G. bab VI: Sântiparva :239,300), dan deskripsl tentang Vlsvapura (Udyogaparva: 170; Aśvamedhoparva:55; Sartparva:339; Vrapare:99). (Radhakrishnan 1929:523).

Mesklpun Bhagavadgîtâ telah ditetapkan sebagal bagłan asll darı cerita Mahâbhârata, akan tetapl mengenal umurnya masth belum dapat dipastikan dengan tepat. Mengenal hal InI terdapat beberapa pendapat yang berlainan. di antaranya lalah Telang yang menelitı baglan pendahuluan Bhagavadgîtâ menyebutkan bahwa Bhagavadgîtâ berasal dart abad ke-3 SM; R.G. Bhandarkar berpendapat bahwa karya Inl tidak leblh tua darl abad ke-4 SM.; Garbe menyebutkan bahwa Bhagavadgitâ yang asli berasal darl abad ke-2 SM., tetapl baru ada bentuknya pada abad ke-2 M.: Radhakrishnan berpendapat bahwa Bhagavadgitâ berasal darı ke-5 SM. la sampal pada kesimpulan tersebut setelah melihat bahwa dalam purana-purana yang berasal darl abad ke-2 $M$. terdapat beberpa gubahan yang dlambll dart Bhagavadgitã. la juga mellhat dalam tulisan Bhâsa, yang diperkdrakan hidup antara abad ke-2 M. sampal abad ke-4 M.. yang berjudul Kamabhâra terdapat baglan yang berasal dart syalr Bhagavadgitâ. dan Bhodayâna dalam tulisannya yang berjudul Gṛya sûtra sangat akrab dengan pemujaan kepada Vasudeva serta dalam deskripsinya mengenal sifatsıfat Bhagavân tampaknya dikutıp dart Bhagavadgîtâ bab XX.26. demiklan pula dalam tullsannya yang berjudul Pițmedra sûtra. Menurut Radhakriohnan. Jlka f̂pastambha berasal dart abad ke-3 SM. dan Bhodhayâna lebth awal satu atau dua abad, maka Bhagavadgîtâ diperkisakan beraeal dart abad ké-5 SM. (RadhakJishnan 1829:524). 


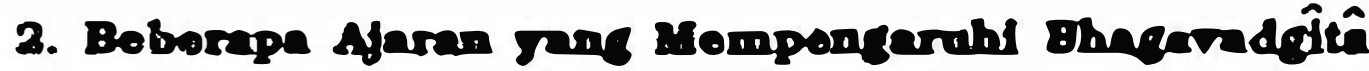

Bhagavadgitã sangat dipengaruhı oleh ajaran-ajaran Veda. Upanisad, Buddhis. Bhâgavata. Samkhya dan Yoga, serta ajaranajaran latnnya yang berpengaruh pada masa itu (Bhandarkar 1913:27: Dasgupta 1952:549-550: Radhakrishnan 1929:525). Latar belakang fllsafat tentang realitas yang tertinggl, ksetra dan kșetrâjña kșara dan akșara. serta bhaktt dalam Bhagavadĝtâ. dlambil darl ajaran Upaṇișad. Ajaran bhaktl itu sendirl merupakan perkembangan langsung dart Upasana Upanisad. Bhagavadgitâ pun dianggap telah bersintesa dengan agama Bhâgavata. bahkan ajaran Bhagavadgitâ Identik dengan doktrin Bhâgavata sehingga pada suatu saat Bhagavadgîtâ disebut sebagal Harigitâ (Radha-krishnan 1929:527). Meskipun Bhagavadgit tâ tudak menyebutkan tentang Bhuddisme, akan tetapl ada beberapa persamaan pandangan Bhagavadgîtâ dengan Buddhisme. antara lain balk Bhagavadgîtâ maupun Buddhis menolak adanya sistem kasta yang kaku dan keduanya merupakan perwujudan dar pergolakan/ revolus! spiritual. Selain itu juga Bhagavadgitâ mengambil beberapa prinsip etkk Buddhisme (Radhakrishnan 1929:527). seperti tindakan manusla yang harus impersonal dan tanpa pamrih.

Menurut pendapat Garbe. Bhagavadgitâ yang ditulis pada abad ke-2 SM.. adalah sebuah risalat thelstlk yang didasarkan pada Sâríkhya-Yoga (Radhakơtshnan 1929:530) Akan tetapl Istilah Sâminkya-Yoga dalam Bhagavadgîtâ ttdak dtuułudkan sepertł pada alıran klastk dart Sâmîhya-Yoga. dalam Bhagavadgîtâ tdak dimujudkan sepert! pada aliran klastir dari Sânkhya-Yoga. tetap! hanya mengambil metocie merenung dan meditas! untuk mem

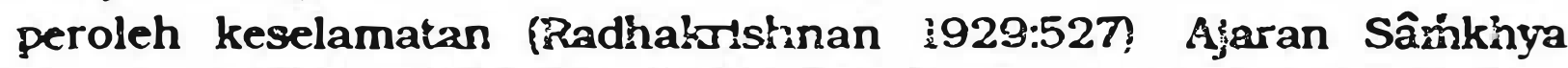
mengenal purusa (roh) dan praḳțt (benda) dimana prakrtt melakukan segala macam aktıvitas dan puruṣa udak melakukan apa-apa. dalam Bhagavadgit $\hat{a}$ ditambahkan dengan fllsasiat mengenal Purusottama atau Jiwa Yang Tertinggi. Ajaran Inilah yang membertkan ctri-cirl thelstik kepada Alsafat Bhagavadgîtâ (Bhandarkar 1913:27).

\section{Tholome dalom Bhagavadốn}

Dalam Bhagavadgîtâ terdapat konsep mengenal Purusorama atau purusa yang tertinggl. yang juga disebut parmamar atau acmar yang tertinggl atau lovara. Dalam 
ajaran InI Krș̣na dianggap sebagal Purusottome. Puruṣottama disebutkan sebagal zat yang tertinggi dalam keadaan tidak tenang karena sudah mempunyal daya penggerak yang disebut 'sakth, sedangkan Brahmar adalah zat yang tertinggi dalam keadaan tenang. Mengenal Brahman, Sarikarananda dalam Commentary on the Gîtâ menyebutkan tentang adanya dua bentuk Vâsudeva, yang berwujud dan tidak berwujud. Parabrahman adalah bentuk yang tidak berwujud (Radhakrishnan 1929:543). Selanjutnya disebutkan Purisottama memiliki dua aspek, yaltu aspek yang tidak dijelmakan. aspek yang tenang serta tidak berubah, dan aspek yang dijelmakan. Purusottama pun mempunyal dua sifat, yaltu sifat yang leb!h tinggi (para) dan sifat yang lebih rendah (aparâ). Dart sifat yang lebih tinggi timbul purusa atau jiwa dan dari sifat yang leblh rendah timbui prakrtl atau asas segala yang bersifat kebendaan (Radhakrishnian 1929:541; Hadiwijono 1929:48-49). Sepertl halnya dalam Smikhya, dalam Bhagavadgîtâ pun disebutkan bahwa puruṣa tidok aktıf tapl hanya sebagal penonton saja, sedangkan prakṭt melakukan segala macam aktıvitas (Radhakrishnan 1929:529).

Penyebab Purusottama menciptakan dunia yang sifatnya fana inl, lalah daya atau kekuatan yang timbul pada Purușottama dengan kekuatan saktınya atau màya Menurut Radhakrishnan. untuk mengetahui teorı tentang mâyâ dalam Bhagavadgîtâ, perlu membedakan beberapa perbedaan dalam pemahaman arti kata mâyâyang terdapat dalam Bhagavadgîtâ. yaltu:

1. Jika realitas tertinggi tidak dipengaruhi oleh peristiwa-peristiwa dunla, lalu meningkatnya peristlwa-peristiwa tersebut menjadi misteri yang tidak dapat dijelaskan. Penulis Bhagavadgîtâ tidak menggunakan istllah mâyâ dalam pemahaman inl, meskipun Istllah tersebut banyak mempengaruht pandanganpandangannya. Di dalam pikiran penulis Bhagavadgitâ tidak ada konsep mengenal sesuatu yang tanpa akhir dan pada saat yang bersamaan merupakan llusı. serta konsep avidyâ yang menyebabkan ilusi dunia.

2. Pribadi Isvara disebutkan sebagal penggabungan sat dan asat dalam dirınya sendirı, kekekalan Brahman juga merupakan mutasi yang selaras. Mâyâ adaiah śakttatau tenaga dar Isvara atau atmavibhut yaitu kekuatan yang datang darl dirinya. Isvara atau mayâ dalam pemahaman inı, keduaiỳ tanpa akhir yang saling bergantung satu sama lain. Kekuatan yang 
tertinggi int vang dalam Bhagavadgîtâ disebut mâyâa.

3. Sajk Tuhan menclptakan alam semesta dengan memakal dua eiemen dart kehadiran Nìa, yaltu prakṛtl dan puruşa vat dan kesadaran Kedua elemen ttu dikatakan sebagal mââ (yang lebih tinggi dan lebih rendah) dari Tuhan

4. Secara berangsur-angsur. mâyâ dianggap sebagal prak!tl yang lebth rendah, oleh karena itu puruṣa dikatakan menjadı bıbit yang dilemparkan Tuhan kedalam rahim prakrtt untuk membangkitkan alam semesta int.

5. Sebagalmana dunia nyata menyembunylkan kenyataan dari pandangan makhluk hidup dan hal itu menjadi llusi didalam sllatnya. Dunia bukanlah suatu llusi, tapi hanya merupakan ketentuan mekanis dari alam yang tidak dihubungkan dengan Tuhan. dan jika manusla gagal memperoleh makna dari esensı ketuhanan maka hal itulah yang menjadi sumber llusl. Ketuhanan mâyâ menjadı avidyâmâyâ. Bagaimanapun, untuk manusla $k \in$ matlan adalah penghentian dari kebenaran. Tuhan yang mengetahul segalanya, mengawasinya dan itu yang disebut dengan vidyâmâyâ mâya bagi manusia merupakan sumber kesukaran dan kesengsaraan, hal itu menyebabkan sebaglan kesadaran menjadi kacau karena kehllangan pegangan tentang realitas yang utuh. Tuhan tampaknya menjadi selimut bagian luar mâyâyang luas sekalı.

6. Sejak dunia hanya dipengaruhi oleh Tuhan, sebagal penyebab, dan karena di mana-mana penyebab lebih nyata daripada pengaruh. maka pengaruh dunia dapat dikatakan tidak begitu nyata daripada sebab yang diciptakan Tuhan. Ketidaknyataan yang relatif dart dunia ini ditegaskan oleh sifat kontradiktif atas proses yang selaras. Ada suatu perjuangan atas pertentangan dalam pengalaman duniawi. tetapi kenyataan yang sesungguhnya adalah di atas semua pertentangan tersebut (Radhakrishnan. 1929: 546-547).

7. Dalam Bhagavadgîtâ XIV.5 terdapat penjelasan bahwa dı dalam prakrtt terdapat tiga sifat yang mengikat manusia yang disebut triguna, yaitu sattva. rajas dan tamas. Sattva lalah stfat terang disebabkan cinta pada pengetahuan (iñana sarigena) dan cinta kepada kesenangan (sukha sarigena); rajas lalah sifat penggerak yang timbul karena hasrat dan cinta (trsnâ-sarigasamudbhavam). sifat inillah yang menyebabkan tindakan egoisme pada 
dir manusla; dan tarnas lalah affat yang sembrono, malas, dan masa bodo karena ketidaktahuan dan membutakan dirl terhadap kehidupan yang ada disekelilingnya. Ketiga stfat int saling menguasal pada waktu yang berlalnan. Jika sattva menguasal rajas dan tamas. maka pada saat tampak peningkatan pengetahuan dan plktran; Jika rajas menguasal sattua dan tamas. maka pikiran akan cenderung pada ketamakan dan usaha untuk meningkatkan nafsu, hasrat, dar! emosl, dan Jika tamas menguasal sattva dan rajas maka yang akan terjadi lalah kebodohan. kelesuan. kesalahan. Ilusl. dan kepercayaan yang salah (Dasgupta 1952:462).

Menurut ajaran Bhagavadgîtâ manusla dapat mencapal tujuan akhlr dengan pengetahuan tentang realitas yang tertingg'

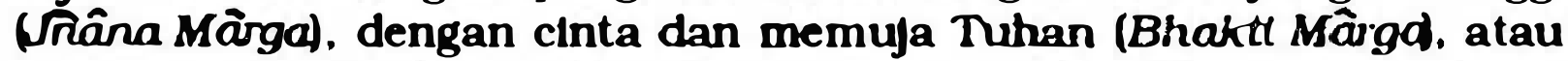
dengan menguasal kemauannya sendin untuk tujuan sucl (Kama Mânga. Ketiga Jalan Inl, meskipun berbeda tapl mempunyal tujuan yang sama yaitu bersatu dengan Brahman. Hal InI dapat terjadi karena Tuhan adalah sat. ctt. dan ânanda yaltu realitas, kebenaran. dan kebahaglaan. Bagl orang yang mencart tujuan akhir dengan pengetahuan tentang realitas yang tertinggi. Tuhan menyatakan diriNya sebagal Cahaya Abadi. Jemih dan bersinar sepertl matahari pada tengah hart serta tidak ada kegelapan. Orang yang mencart tujuan akhir dengan menundukkan dirl sendirl dan berjuang untuk kebajlkan. Tuhan menyatakan dirinya sebagal Kebenaran Abadi, yang teguh dan tidak memthak. Orang yang mencart tujuan akhirnya dengan cinta dan permujaan terhadap Tuhan. Tuhan menyatakan dirlNya sebagal Cinta Abadi dan Kelndahan dart Kesuctan (Radraloriohnan 1929:553: Hadtwlijono 1985:50). Menurut Madhucadana Sarasvatl. Bhagavadgita mengambll tiga Jalan mencapal tujuan akhir itu dart ajaran Upanlead mengenal kama atau perbuatan, upâsanâ atau pemujaan. dan Jnâna atau kebijakan (Radhakriohnan 1929:554).

sdapun ketiga jalan menuju tujuan akhir dalam Bhagavadgita diuralkan sebagal bertkut:

(1) Jĩana Marga lalah Jalan menuju tujuan akhir melajuj pengetahuan. Menusta akan mendapatkan kebenaran tertlngg! jlka mengetahul Atman adalah Brohman. Bhagavadgitâ mengakul ada dua macam pengetahuan yaltu yang mencart pemahaman 
gejala-gejala dart eksistensi yang dart luar melalul daya pikir, dan suatu pengetahuan yang didapat dari kekuatan intulsi yang blea menangkap asas-asas yang berada di balik gejala-gejala itu. Pengetahuan llinlah disebutkan didominasi oleh rajas ketika pengetahuan spiritual diresap! oleh sifat sattva. Jika manusla mempunyal pengetahuan yang rendah. maka slfat yang menonjol adalah tamas. Untuk memperoleh plkdran yang mantap diperlukan latuhan inental, dan untuk melatih mental Bhagavadgita mengambil sistem Yoga meskipun tJdak sesistematis Pantanjali Sutra. Tahap-tahap pokok dalam melakukan samadhi, yang merupakan tahap kedelapan darı Patanjall Yoga adalah: (1) mensuctkan ptktran, tubuh. dan perasaan sehingga dimasukd oleh yang maha kuasa: (2) mengosongkan plkıran darl gerakan plkiran yang bercabangcabang yang menuju sasaran dunlawl dan mengkonsentrasıkan plkiran kepada yang tertinggi: dan (3) setelah mencapal pemusatan pemikiran kemudian mengidentifkastkan dirı dengan yang tertinggi/kebenaran (Radhakrishnan 1929:556).

(2) Bhaktt Mârga lalah Jalan menuju pelepasan melalul kasth sayang dan pemujaan kepada Tuhan. Bhaktt laiah emosl kasth sayang yang berbeda dengan pengetahuan atau perbuatan. Emosi memperlihatkan hubungan kehidupan antar individu. dan menjadı nalur bag! kekuatan perasaan religius yang menglkat Tuhan dengan manusla. Jlka seseorang tidak mencintal dan memuja Tuhan maka la akan terpenjara dalam keegolsan. Dengan Jalan menclntal dan memuja Tuhan maka akan mencapal persepsi yang tertungg1. Dalam bab LX32 dan XI.53-54 disebutkan bahwa bhakt terbuka bagi semua orang. bagi yang lemah dan bagi yang rendah. bagi yang buta huruf dan bagi yang bodoh. serta merupakan cara yang tennudah untuk dijalankan. Kurban dengan cinta ticakiah sestisah seperti disiplin ascotlk maupun usaha yang kuat dari berplkir (Radhakrisnan 1929:558-559). Ajaran menggenal biakti ini diambil dari teori Upasana darı Upanışad dan cara berbaktı darı ajaran Bhagavata (Radhakrishnan 1929:559). Obyek dart bhakt lalah kehadiran Yang Tertinggl atau Purusottama Purusottama laiah memberl cahaya jtwa dan pemberlan kehidupan dunla. Bhaktl menurut Bhagavadgîtâ lalah percaya kepada Tuhan, mencintalNya. mentaatiNya, dan maouk kedalamNya. Untuk bhakt yang benar 
diperiukan oraddha atau kepercayaan Radhakrohnan 1929:561 562). Bhagavadgita yang menganggap avatara dewa lebih rendah dar pada Punspottana demildan pula Brahma, Visnu, dan çiva sebagai penetpta, pelindung, dan peruaak dunla ditempatkan lebth rendah dari Pouscocama masth tetap mengakul pemujaan kepada dewa-dewa Veda. Rarena bagl Bhagavadgita

(3) Kame Mânga lalah mencapal tujuan akchir dengan melalul karma atau perbuatan. Bhagavadgita mencoba mempersatukan pandangan-pandangan yang berbeda mengenal perbuatan dari ajaran Veda, Upanlsad dan Buddhls ke dalam satu sistem yang konsisten (Radhakrishnan 1929:566). Dalam ajaran ini ditekankan agar manusla selalu berbuat kebajlkan dan harus melepaskan keegolsannya. Nafsu, kemarahan, dan ketamakan adalah perbuatan yang dapat diatasl dengan melakukan kebajlkan.

\section{Avatâra}

Yang dimaksud dengan avatâra lalah Inkarnası Tuhan menjadi manusla ataupun makhluk laln sebagal Juns Selamat manusla dengan kekuatan-kekuatan yang menakjubkan. Maksud darı Avatâra lalah untuk menyelamatkan manusla darı kekuatankekuatan Jahat yang hendak menghllangkan nilal-nilal kemanuslaan. Hal Inl karena Sang Penclpta atau Puruşottama tidak dapat dipleahkan darl clptaannya (Radhakrishnan 1929:546). Mengenal Inkarnasi Tuhan sebagal Juru Selamat dapat dilihat dalam Bhagavadgitâ bab IV.7-8 yang menyebutkan "Apablla kebenaran telah mengendur dan kejahatan makm berkuasa. Aku clptakan dirtKu sendirl. Aku lahir darl masa ke masa untuk meltndungl yang balk dan menghancurkan tindakan yang salah, serta menegakkan hutkum (Radhakrishnan 1929:546).

Ada beberapa sumber yang menyebutkan jưnlah avatâra Vienu yang berbeda. Nââyanika menyebutkan ada enam Avatara Vionu, yaltu sebagal babi hutan, manusla-singa, orang kerdil, Râma darı wangea Bḥ̣gu, Ràma Dâsarathı, dan KỴ̣na. Dan ada pendapat lainmya yang menyebutkan sepuluh avatâra Vig̣nu dengan menambahkan Hamsa (angea). Kî́ma (kura-kura). Matsya (1kan). dan Kalkd. Hartuarrsa mengemukakan dua Jumlah avatâra Viọnu yang berbeda. yaltu sepuluh dan duabelas avatara. Dalam VorahaPurma dan Agnt Puṇ̃a disebutkan sepuluh avatâra. Sedangkan 
dalam Bhãgavata-P wầa disebutkan tiga jumlah avatâra Viģṇu yang berbeda, yastu dalam bab III Buku I terdapat duapuluhdua avâtara, dalam bab 7 Buku II terdapat duapuluntiga avatâra, dan dalam bab 4 Buku XI terdapat enambelas avatâra (Bhandarkar 1913:41-42).

Dalam Bhagavadgî́a disebutkan ada sepuluh avatâra (dâsâuatâra) Viọnu. dimulal darı tingkat yang paling rendah berwujud blnatang. yaitu sebagal lkan (Matsyâuatâra) yang menolong Manu (manusla pertama) untuk menghindarkan dirl dari alr bah yang menghancurkan dunla: sebagal kura-kura (homâuatâra) yang berdirı di atas laut untuk menjadı alas Gunung Mandara yang digunakan para dewa untuk mencari Amrta; dan sebagal babi hutan (variahâvatâra) yang mengangkat dunla kembali ke tempatnya, ketika dunia ditelan dan ditartk ke dalam kegelapan patala (dunla bawah). Penjelmaan yang kemudian berupa transisl antara binatang dan manusla. yaitu sebagal singa-manusla Narastinhâuatâra) yang membunuh Hirañakasipu. raksasa yang menguasal dunla dengan lalimnya. pada senja hart karena dia tidak dapat mats pada waktu slang ataupun malam, tidak dapat dibunuh oleh dewa. manusla. maupun binatang. Lalu berkembang menjadi manusla walaupun tidak seperti manusta yang normal. perwujudannya adalah sebagal manusia kerdil (vônanâvatâra) yang minta kepada Daitya Ball yang sangat lalim memerintah dunla supaya diberikan tanah seluas tiga langkah. Setelah ditjinkan maka dengan tiga langkah (trlutikramat la menguasal dunia. angkasa. dan surga. Inngkat avatara yang menjelma menjadı manusla. dimulal dengan manusia yang kasar bengis, tidak berbudaya, yaltu sebagal Rầna dengan kapaknya (Paraçurânâuatồa yang menghancurkan kaum Ksatrya sebagal balas dendam terhadap penghinaan seorang raja kepada ayahnya. seorang brahmana: kemudian sebagal Rama îâmâuatâra yang mengabdi dan mencintal keluarganya. memerangi Rahvẩna atau Dasamukha yang mengancam keselamatan dunia: lalu menjelma menjadi Kụsna (Krșna-vatâra) yang mendesak manusla untuk masuk ke kancah peperangan di dunla. dalam rangka membantu Pandava menuntut ikeadllan dar! Kaurava; setelah itu menjelrna menjadi Buddha (Buddhâuatâra) yang menylarkan agama palsu guna menyesatkan mereka yang memusuht dewa dan yang terakhir menjelma menjadi Kalki Kalkyâuatâna yang mengendaral kuda putih dengan bersenjatakan pedang di tangannya menantang kejahatan dan ketidakadilan 


\section{B. Penatup}

Bhagavadgitã merupakan suatu ajaran yang menampung semua ajaran yang berpengaruh pada saat Itu, sepertl Veda. Upanişad. Buddhis. Bhâgavata. serta Sârikhyya dan Yoga. dan mencoba menerapkannya ke dalam kehidupan sehart-hart.

Bhagavadgita menawarkan tiga jalan untuk mencapal tujuan akhir atau moksa kepada setlap orang, tanpa plith buks. Adapun ketiga Jalan tersebut lalah pertama jñâra mârga, yaltu mencapal tujuan akhir dengan melalul pengetahuan. kedua bhaktt mãrga yaltu mencapal tujuan akhir dengan kasth sayang dan permujaan kepada Tuhan: dan ketiga karma mârga. yaltu mencapal tujuan akhir dengan melalul perbuatan.

Dart ketiga jalan tersebut, yang telah sampal pada ajaran thelstlk lalah bhaktı mâga yang menganjurkan pemujaan kepada Tuhan atau Purıșottamadengan percaya kepadaNya. mencintalNya. dan mentaatiNya. Pengertlan mengenal Prususottama Inllah yang membedakan fllsafat Bhagavadgîtâ dengan Sânkthya-Yoga. Dalam penjelasannya mengenal Puruşottama yang pada hakekatnya adalah Tuhan Yang Maha Esa. Bhagavadgitâ sudah mulal memperlihatkan ciri-ciri theistik. 


\section{Expotetaran}

Bhandarkar Sir RG. 1913, Mrmantm. Cadram, and Minor rellglue Gyotem. Strascbung: Verlag von Karl J. Trubner.

Dasgupta. Sarendranath. 1952. A Filotory of Indian Philleophy. volume II. London: The Syndics of the Cambridge Untversity Press.

Hadtwijono. Harun. 1985. 8art Pllenfat India. Jakarta: BPK Gunung Mulla.

Pudja. G. 1885/1986. Bhagevadolta (Fencama Woda). Jakarta: Maya Sari.

Radhakrishnan. 1929 Indian Philosophy, volume I. London: Goenge Allen \& Unwin Ltd.

Soekmono, R 1973 Eojarab Kobedayann Indonoola. Jilld kedua. Jakarta: Penerbitan Yayasan Kanistus. 